\title{
Pharmaceutical drug promotion: perception and attitude of medical interns towards drug company interactions in a tertiary care teaching hospital
}

\author{
Chandan N. G.*, Shashikumar N. S., Nagabushan H.
}

Department of Pharmacology, Mandya Institute of Medical Sciences, Mandya, Karnataka, India

Received: 30 March 2017

Accepted: 27 April 2017

*Correspondence to:

Dr. Chandan N. G.,

Email: drchandanng81@

yahoo.com

Copyright: () the author(s), publisher and licensee Medip Academy. This is an openaccess article distributed under the terms of the Creative Commons Attribution NonCommercial License, which permits unrestricted noncommercial use, distribution, and reproduction in any medium, provided the original work is properly cited.

\begin{abstract}
Background: Interactions of pharmaceutical industry with the physicians which are usually mediated through pharmaceutical representatives have a significant impact on physician decision-making. This interaction can start as early as medical school during their training and this is said to influence their prescribing behavior when they become physicians. Aims and objectives of the study was to evaluate the attitude of interns towards pharmaceutical companies interactions including accepting gifts, ethical issues and influence on clinical decisions and also to study perception of medical interns towards the accuracy of information provided by the medical representatives.

Methods: This was a cross sectional questionnaire based study that was conducted among the medical interns of the teaching hospital attached to Mandya Institute of Medical Sciences, Mandya. The study was carried out between July and August 2016. A preformed structured questionnaire was distributed to the interns consenting to participate in the study. Completed questionnaires were collected, compiled and data was analyzed.

Results: A total of 93 questionnaires were distributed and 90 interns responded (response rate $96.7 \%$ ). About $44.4 \%$ respondents felt that accepting gifts from Drug Company would influence their own decision making. Only $26.6 \%$ of them were of the opinion that it is ethical to accept pharmaceutical company gifts. Majority of them felt that Medical Representatives exaggerate the benefits of medicines and downplay the risks and contraindications of medicine. About $32.2 \%$ of them were of the opinion that they would prefer to prescribe the drug from the companies offering them with gifts over those without. Majority of the respondents felt that the doctors should be offered with gifts by drug companies whenever their drugs are prescribed.

Conclusions: Attitude of Medical Interns towards Drug Company interactions as observed suggests for training the budding doctors on appropriate drug company interactions to prevent the risks associated with promotional efforts of pharmaceutical companies.
\end{abstract}

Keywords: Attitude, Drug company gifts, Drug company interactions, Interns, Medical representatives

\section{INTRODUCTION}

The pharmaceutical industry spending on promotional activity for marketing their products runs in billions of dollars. Personal interactions of pharmaceutical industry with the physicians which are usually mediated through pharmaceutical representatives make the highest share of this spending. ${ }^{1}$ Various services and gifts are offered by pharmaceutical industry to the physician that includes meals, continued education that covers travel expenses, drug samples, and research sponsors. ${ }^{2}$ There is notable evidence to suggest that this relationship has a significant impact on physician decision-making. ${ }^{3,4}$ Also, in various studies it has been observed that the drug information provided by the pharmaceutical industry usually highlights their benefits and give less importance to their risks. This results in increase of their prescription..$^{5-7}$ Interaction with pharmaceutical representatives was found to have resulted in irrational prescription and hence increasing the cost of treatment. ${ }^{8,9}$ 
The interaction between medical professionals and pharmaceutical industry can start as early as medical school. The medical professionals during their training benefit from industry-sponsored meals, free samples and small gifts such as pens and textbooks. This is said to influence their prescribing behavior when they become physicians. ${ }^{10}$ Medical trainee's knowledge about professional ethics in interacting with drug companies and accuracy of drug information from medical representatives are found to be deficient. ${ }^{11}$ Hence this study was undertaken to evaluate the attitude and perception of interns towards drug company interactions.

\section{Objectives of the study}

- To evaluate the attitude of medical interns towards pharmaceutical companies interactions including accepting gifts, ethical issues and influence on clinical decisions.

- To study the perception of medical interns towards the information provided by the medical representatives.

\section{METHODS}

\section{Study design}

This was a cross-sectional questionnaire based study that was conducted in the teaching hospital attached to Mandya Institute of Medical Sciences, Mandya.

\section{Study population}

This study was conducted among medical interns working in this teaching hospital. Only those who gave their consent to participate were included in the study.

\section{Study tool}

A structured questionnaire was developed after reviewing the relevant literature and the questionnaires used in similar studies. ${ }^{12-14}$ The questionnaire was also validated by the subject experts for its content and relevance. The first section of the questionnaire involved the demographic data of the participant such as age, sex, and address. The second section of the questionnaire involved questions to evaluate the attitude of interns towards drug company interactions and also to assess their perception towards the information provided by medical representatives.

A 4-point Likert scale whose response ranges from strongly agrees to strongly disagree was used in this section. The third section of questionnaire involved questions to evaluate their attitude towards the gifts offered by medical representatives. A 3-point Likert scale with the response as always, sometimes and never was used in this section. The fourth section of the questionnaire involved list of various gifts offered by the drug companies and the participants were asked to rate their appropriateness.

\section{Study procedure}

Each medical intern was explained the objectives of the study and their willingness to participate in the study were obtained. After which the questionnaire was distributed and they were asked to complete it anonymously. Completed questionnaires were collected and analyzed.

\section{Statistical analysis}

Descriptive statistical analysis was used to generate frequencies, percentage and proportions. Chi-square test was also used at appropriate places to determine the statistical significance. Statistical significance was established when the probability value was less than 0.05 .

\section{RESULTS}

A total of 93 questionnaires were distributed among the medical interns and 90 questionnaires were returned with complete response. The response rate of the study was $96.7 \%$. Among the participants 42 were males and 48 were females. The mean age of the respondents was 22.8 years.

Table 1 indicates the attitude and perception of interns towards drug company interactions and information provided by medical representatives. In this study it was observed that $27.8 \%$ of the participants agreed and $8.9 \%$ of them strongly agreed that medical representative's visit is the only way to learn about new drugs. Majority of them disagreed $(56.6 \%)$ with the statement that medical representatives are a source of correct information about drugs and have a valuable teaching role.

About $57.8 \%$ of the participants agreed that medical representatives exaggerate the benefits of medicines and downplay the risks and contraindications of medicine. With regard to receiving gifts or food from medical representatives, many $(38.9 \%$ agreed and $5.5 \%$ strongly agreed) of them felt that the chance of prescribing that Drug company's product will increase. About a quarter participants felt that it is ethical to accept pharmaceutical company gifts.

With regard to the CMEs and Lectures sponsored by the pharmaceutical company, 75.6\% (68.9\% Agreed and 6.7\% Strongly agreed) of the interns felt that they were informative and useful. Also, majority $(61.1 \%$ Agreed and $5.5 \%$ Strongly agreed) of them were of the opinion that the Drug company-sponsored lectures or CME events are often biased in favor of the company's products.

When asked about their opinion on receiving financial support from the drug companies for a CME/Conference, $71 \%$ (65.5\% Agreed and 5.5\% Strongly agreed) of the interns think it to be acceptable.

About $87.7 \%$ of the interns felt the need for strengthening of ethical norms to regulate the physician-pharmaceutical industry interaction. 
Table 1: Attitude and perception of interns towards drug company interactions and information provided by medical representatives.

\begin{tabular}{|c|c|c|c|c|}
\hline Statement & $\begin{array}{l}\text { Strongly } \\
\text { agree } \\
(\mathbf{N}=90) \\
\text { n }(\%)\end{array}$ & $\begin{array}{l}\text { Agree } \\
(\mathbf{N}=90) \\
\mathbf{n}(\%)\end{array}$ & $\begin{array}{l}\text { Disagree } \\
(\mathbf{N}=90) \\
\mathbf{n}(\%)\end{array}$ & $\begin{array}{l}\text { Strongly } \\
\text { disagree } \\
(\mathbf{N}=90) \\
\mathbf{n}(\%)\end{array}$ \\
\hline Medical representative visit is the only way to learn about new drugs & $08(8.9)$ & $25(27.8)$ & $48(53.3)$ & $9(10)$ \\
\hline $\begin{array}{l}\text { Medical representatives are a source of correct information about } \\
\text { drugs and have a valuable teaching role }\end{array}$ & $04(4.4)$ & $23(25.5)$ & $51(56.6)$ & $12(13.3)$ \\
\hline $\begin{array}{l}\text { Medical representatives exaggerate the benefits of medicines and } \\
\text { downplay the risks and contraindications of medicine }\end{array}$ & $21(23.3)$ & $52(57.8)$ & $17(18.9)$ & 00 \\
\hline $\begin{array}{l}\text { Receiving gifts or food from Medical representatives increases the } \\
\text { chance that I will eventually prescribe the drug company's products }\end{array}$ & $05(5.5)$ & $35(38.9)$ & $45(50)$ & $05(5.5)$ \\
\hline It is ethical to accept pharmaceutical company gifts & $05(5.5)$ & $19(21.1)$ & $51(56.6)$ & $15(16.7)$ \\
\hline $\begin{array}{l}\text { Most lectures or CME events sponsored by pharmaceutical companies } \\
\text { are helpful and informative }\end{array}$ & $06(6.7)$ & $62(68.9)$ & $22(24.4)$ & 00 \\
\hline $\begin{array}{l}\text { Drug company-sponsored lectures or CME events are often biased in } \\
\text { favor of the company's products }\end{array}$ & 05 (5.5) & $55(61.1)$ & $30(33.3)$ & 00 \\
\hline Drug company materials are a useful way to learn about new drugs & $08(8.9)$ & $60(66.7)$ & $15(16.7)$ & $07(7.7)$ \\
\hline $\begin{array}{l}\text { It is acceptable to receive financial support from the drug companies } \\
\text { for a CME/Conference }\end{array}$ & $05(5.5)$ & $59(65.5)$ & $23(25.6)$ & $03(3.3)$ \\
\hline $\begin{array}{l}\text { There is a need for strengthening of ethical norms to regulate the } \\
\text { physician-pharmaceutical industry interaction }\end{array}$ & $21(23.3)$ & $58(64.4)$ & $11(12.2)$ & 00 \\
\hline
\end{tabular}

Table 2: Attitude of the interns towards the gifts offered by medical representatives.

\begin{tabular}{|llll|}
\hline Statement & $\begin{array}{l}\text { Always } \\
(\mathbf{N}=90) \\
\mathbf{n}(\%)\end{array}$ & $\begin{array}{l}\text { Sometimes } \\
(\mathbf{N}=90) \\
\mathbf{n}(\%)\end{array}$ & $\begin{array}{l}\text { Never } \\
(\mathbf{N}=90) \\
\mathbf{n}(\%)\end{array}$ \\
\hline $\begin{array}{l}\text { Gifts should be } \\
\text { given to doctors }\end{array}$ & $10(11.1)$ & $60(66.7)$ & $20(22.2)$ \\
\hline $\begin{array}{l}\text { Gifts are } \\
\text { necessary }\end{array}$ & $08(8.9)$ & $40(44.4)$ & $42(46.7)$ \\
\hline $\begin{array}{l}\text { Prescribe only } \\
\text { drugs coupled } \\
\text { with gifts }\end{array}$ & $08(8.9)$ & $21(23.3)$ & $61(67.8)$ \\
\hline $\begin{array}{l}\text { Will accept gifts } \\
\text { if offered }\end{array}$ & $23(25.6)$ & $47(52.2)$ & $20(22.2)$ \\
\hline
\end{tabular}

Table 2 indicates the attitude of the interns towards the gifts offered by medical representatives. In this study we observed that $77.8 \%$ of the respondents felt that the doctors have to be offered gifts by Drug Company whenever their drugs are prescribed. Although 53.3\% of the interns think that gifts by pharmaceutical company are necessary, only about $32.2 \%$ of the participants preferred to prescribe drugs from the companies that offer them with gifts.

Table 3 gives the interns assessment of the appropriateness of the gifts from the pharmaceutical company. Gifts in the form of stationary items (82.2\%), textbooks (88.9\%), travel to conference $(72.2 \%)$ and drug samples $(91.1 \%)$ were considered to be appropriate by majority of the respondents in this study. Relatively lesser respondents considered sponsored meal (35.5\%), social outing (35.5\%) and vacation $(27.8 \%)$ by Drug Company as appropriate.
All the above responses were found to be statistically significant.

Table 3: Appropriateness rating by the interns for the gifts offered by drug company.

\begin{tabular}{|llll|} 
Statement & $\begin{array}{l}\text { Appropriate } \\
(\mathbf{N}=90) \\
\mathbf{n}(\%)\end{array}$ & $\begin{array}{l}\text { Inappropriate } \\
(\mathbf{N}=90) \\
\mathbf{n}(\%)\end{array}$ & $\mathbf{P}$ \\
\hline $\begin{array}{l}\text { Stationary } \\
\text { items }\end{array}$ & $74(82.2)$ & $16(17.8)$ & $<0.0001$ \\
\hline Meal & $32(35.5)$ & $58(64.5)$ & 0.024 \\
\hline Textbook & $80(88.9)$ & $10(11.1)$ & $<0.0001$ \\
\hline $\begin{array}{l}\text { Travel to } \\
\text { conference }\end{array}$ & $65(72.2)$ & $25(27.8)$ & 0.0005 \\
\hline $\begin{array}{l}\text { Social } \\
\text { outing }\end{array}$ & $32(35.5)$ & $58(64.5)$ & 0.024 \\
\hline $\begin{array}{l}\text { Drug } \\
\text { samples }\end{array}$ & $82(91.1)$ & $08(8.9)$ & $<0.0001$ \\
\hline Vacation & $25(27.8)$ & $65(72.2)$ & 0.0005 \\
\hline
\end{tabular}

\section{DISCUSSION}

This study was conducted to assess the perception and attitude of medical interns towards drug company interactions. About one third of the participants in our study felt medical representative visits as the only way to learn about new drugs. A similar response was observed in a study conducted by Hodges on residents, interns and clerks working in the psychiatry department, where less than one third of them were of the opinion that representatives provided useful and accurate information 
on new and established drugs. ${ }^{15}$ In our study around three fourth of the respondents considered drug company materials a useful way to learn about new drugs. A similar response has been reported in a study by Sierles et al. ${ }^{16}$ Another study by Austad et al has reported smaller number of residents $(45.5 \%)$ agreeing with that fact. ${ }^{17}$ Although more than $80 \%$ of the respondents in our study felt that the Medical representatives exaggerate the benefits of medicines and downplay the risks and contraindications of medicine, many of them still consider Medical representatives as source of correct information and value their teaching role. Hodges also observed a similar response with regard to the teaching role of pharmaceutical representatives. ${ }^{15}$ Beyhun et al on asking this question to medical trainees in a different way observed that the information provided by drug company representatives was not found to be impartial by majority of the respondents. But still many of them felt interactions with drug company representatives as an important source of information. ${ }^{18}$ This finding may be a matter of concern as drug information provided by the pharmaceutical representatives was often found to be incomplete with information on adverse effects and risks being omitted or mentioned less frequently. ${ }^{19}$ Inadequate information especially with regard to the hazards or risks associated with the drugs, probably affects the decision making, eventually resulting in adverse health outcomes.

Although majority of the respondents in our study considered the Drug Company sponsored lectures or CMEs to be biased in favour of company's product, around three fourth of the participants still consider Drug Company sponsored lectures or CMEs to be helpful and informative. The response in our study was found to be similar to the one observed by Sierles et al for the sponsored grand rounds. ${ }^{16}$ Also, majority of the participants in this study were found to have permissive attitude towards acceptance of financial support from the drug companies for a CME/Conference.

Drug company sponsored CME programs is likely to have an impact on the prescribing behavior of the physicians. ${ }^{20}$ Medical trainees in particular are more vulnerable to the marketing maneuvers by the Drug Company representatives. ${ }^{21,22}$ It is important to have some regulations to get rid of the conflict of interest in physician practice under Drug Company influence. One of the suggestions by an American workgroup to the Academic medical centers to reduce the influence of Drug companies on CMEs was to prohibit drug companies from supporting directly or through any subsidiary agency to any CME programs accredited by Accreditation Council for Continuing Medical Education (ACCME), instead to have a central depository to which a Drug Company willing to support a medical education program can hand out. Such funds can then be utilized for various ACCME- accredited programs. This system can minimize the influence of companies making the sponsor. ${ }^{23}$
Pharmaceutical company's promotional activity also includes offering promotional gifts to the physicians. ${ }^{2}$ More than half of the participants in this study felt that accepting gifts from Drug Company will not be influencing the prescribing behavior. A similar response was observed in a study by Sierles et al. ${ }^{16}$ Also, with regard to the appropriateness of various gifts offered by Drug companies, majority of the participants in this study considered stationary items, drug samples, textbooks, and travel to conference to be appropriate. However, a vacation, social outing and meal sponsor by the Drug Company was considered to be inappropriate by the majority of the medical trainees in this study. Sierles et al also observed a similar response in their study except that sponsored meal was considered as appropriate and drug samples were considered to be inappropriate by majority of the participants in their study. ${ }^{16}$ Beyhun et al have also reported that the final year medical trainees in their study were found to be permissive for Drug Company sponsor for travel to scientific meetings. ${ }^{18}$

Receiving gifts from Pharmaceutical companies are found to have an influence on the attitude of the physicians towards Drug company representatives. ${ }^{23}$ Even trivial gifts from the Drug Company is said to have influence on the behaviour. ${ }^{24}$ Since medical trainees may not recognize small gifts to have any influence on decision making, they may be vulnerable to the effects of gifts from the Drug Company. Although, restricting interactions of Medical interns with Drug Company representatives can avoid the adverse consequences of those interactions, they may be left unprepared to deal with promotional strategies of Drug companies after the completion of internship. Change in the attitude of medical trainees towards pharmaceutical company interactions following a workshop has been observed by Wofford et al. ${ }^{21}$ Hence, it is important to train the medical trainees in dealing with Drug Company representatives whom them get in contact during their career. $^{21,25,26}$

The medical curriculum can have educational interventions to teach the medical trainees about having an appropriate interaction with the drug company representatives. Also, there is a need for strengthening of ethical norms to regulate the physician-pharmaceutical industry interaction which was also felt my majority of the participants in our study.

\section{CONCLUSION}

Our study has generated information regarding the attitude and perception of medical interns towards Drug Company interactions and the results suggests for sensitizing and preparing the medical trainees on appropriate interactions with pharmaceutical representatives.

Funding: No funding sources Conflict of interest: None declared

Ethical approval: The study was approved by the Institutional Ethics Committee 


\section{REFERENCES}

1. Austad KE, Avorn J, Franklin JM, Campbell EG, Kesselheim AS. Association of marketing interactions with medical trainees' knowledge about evidencebased prescribing: results from a national survey. JAMA Intern Med. 2014;174(8):1283-90.

2. Moynihan R. Who pays for the pizza? Redefining the relationships between doctors and drug companies. 1: entanglement. BMJ. 2003;326:1189-92.

3. Lexchin J. Interactions between physicians and the pharmaceutical industry: what does the literature say? CMAJ, 1993;149:1401-07.

4. Wazana A. Physicians and the pharmaceutical industry: is a gift ever just a gift? JAMA. 2000;283:373-80.

5. Villanueva P, Peiro' S, Librero J, Pereiro' I. Accuracy of pharmaceutical advertisements in medical journals. Lancet. 2003;361:27-32.

6. Mintzes B, Lexchin J, Sutherland JM, Beaulieu MD, Wilkes MS, Durrieu G et al. Pharmaceutical Sales Representatives and Patient Safety: A Comparative Prospective Study of Information Quality in Canada, France and the United States. J Gen Intern. 2013;28:1368-75.

7. Prosser H, Almond S, Walley T. Influences on GPs' decision to prescribe new drugs-the importance of who says what. Fam Pract. 2003;20:61-8.

8. Halperin EC, Hutchison P, Barrier RC. A populationbased study of the prevalence and influence of gifts to radiation oncologists from pharmaceutical companies and medical equipment manufacturers. Int $\mathbf{J}$ Radiat Oncol Biol Phys. 2004;59:1477-83.

9. Caudill TS, Johnson MS, Rich EC, McKinney WP. Physicians, pharmaceutical sales representatives, and the cost of prescribing. Arch Fam Med. 1996;5:201-6.

10. Rogers WA, Mansfield PR, Braunack AJ, Jureidini JN. The Ethics of pharmaceutical Industry relationships with medical students. Med J Aust. 2004;180(8):411-4.

11. Monaghan MS, Galt KA, Turner PD, Houghton BL, Rich EC, Markert RJ et al. Student understanding of the Relationships between the Health Professions and the Pharmaceutical Industry. Teach Learn Med. 2003;15:14-20.

12. Ingole S. Attitudes of Medical Students Towards Relationship With Pharmaceutical Company: Do We Need A Change? International Journal of Pharma Sciences and Research. 2011;2(2):45-57.

13. Gupta SK, Nayak RP, Sivaranjani R. A study on the interactions of doctors with medical representatives of pharmaceutical companies in a Tertiary Care Teaching Hospital of South India. J Pharm Bioall Sci. 2016;8:47-51.

14. Alosaimi FD, Al Kaabba A, Qadi M, Albahlal A, Alabdulkarim Y, Alabduljabbar M et al. Physicians' attitudes towards interaction with the pharmaceutical industry. East Mediterr Health J. 2015;20(12):812-9.
15. Hodges B. Interactions with the pharmaceutical industry: experiences and attitudes of psychiatry residents, interns and clerks. CMAJ. 1995;153(5):5539.

16. Sierles FS, Brodkey AC, Cleary LM, McCurdy FA, Mintz M, Frank J et al. Medical students' exposure to and attitudes about drug company interactions: a national survey. JAMA. 2005;294(9):1034-42.

17. Austad KE, Avorn J, Franklin JM, Kowal MK, Campbell EG, Kesselheim AS. Changing interactions between physician trainees and the pharmaceutical industry: a national survey. J Gen Intern Med. 2013;28(8):1064-71.

18. Beyhun NE, Kolayli CC, Can G, Topbas M. Turkish Final Year Medical Students' Exposure to and Attitudes Concerning Drug Company Interactions: A Perspective from a Minimally Regulated Environment for Medical Students. PLoS One. 2016;11(12).

19. Othman N, Vitry AI, Roughead EE, Ismail SB, Omar K. Medicines information provided by pharmaceutical representatives: a comparative study in Australia and Malaysia.BMC Public Health. 2010;10:743.

20. Lieb K, Scheurich A. Contact between doctors and the pharmaceutical industry, their perceptions, and the effects on prescribing habits. PLoS One. 2014;9(10).

21. Wofford JL, Ohl CA. Teaching appropriate interactions with pharmaceutical company representatives: the impact of an innovative workshop on student attitudes. BMC Med Educ. 2005;5(1):5.

22. Sandberg WS, Carlos R, Sandberg EH, Roizen MF. The effect of educational gifts from pharmaceutical firms on medical students' recall of company names of products. Acad Med. 1997;72:916-18.

23. Brennan TA, Rothman DJ, Blank L, Blumenthal D, Chimonas SC, Cohen JJ. Health industry practices that create conflicts of interest: a policy proposal for academic medical centers. JAMA. 2006;295(4):42933.

24. Grande D, Frosch DL, Perkins AW, Kahn BE. Effect of exposure to small pharmaceutical promotional items on treatment preferences. Archives of Internal Medicine. 2009;169(9):887-93.

25. Sagarin BJ, Cialdini RB, Rice WE, Serna SB. Dispelling the illusion of invulnerability: the motivations and mechanism of resistance to persuasion. Journal of Personality of Psychology. 2002;83(3):526-41.

26. McCormick BB, Tomlinson G, Brill-Edwards P, Detsky AS: Effect of restricting contact between pharmaceutical company representatives and internal medicine residents on post training attitudes and behavior. JAMA. 2001;286:1994-99.

Cite this article as: Chandan NG, Shashikumar NS, Nagabushan H. Pharmaceutical drug promotion: perception and attitude of medical interns towards drug company interactions in a tertiary care teaching hospital. Int J Basic Clin Pharmacol 2017;6:1456-60. 